\title{
Health care of children diagnosed HIV positive before 18 months in Chea Chumneas Hospital, Takhmao, Cambodia
} Denisa Augustinova*1, Born Ban ${ }^{1}$, Chhunly Kong ${ }^{2}$, KimSong La ${ }^{1}$, Suos Prem Prey ${ }^{3}$, Mealin Kong ${ }^{2}$, Sopheak Ngin ${ }^{4}$, Eric Nerrienet ${ }^{4}$ and Martin Bandzak ${ }^{1}$

Address: ${ }^{1}$ Magna Children at Risk, Bratislava, Slovakia, ${ }^{2}$ Chey Chumneas Referral Hospital, Takmao, Kandal province, Cambodia, ${ }^{3}$ The National Centre for HIV/AIDS Dermatology and STDs, Phnom Penh, Cambodia and ${ }^{4} \mathrm{HIV} /$ Hepatitis Laboratory, Institute Pasteur, Phnom Penh, Cambodia

* Corresponding author

from Fifth Dominique Dormont International Conference. Mother-to-child transmitted viral diseases: from transmission to children care Paris, France. 26-28 March 2009

Published: 22 July 2009

Retrovirology 2009, 6(Suppl I):PI5 doi:I0.I 186/I742-4690-6-SI-PI5

This abstract is available from: http://www.retrovirology.com/content/6/SI/PI5

(c) 2009 Augustinova et al; licensee BioMed Central Ltd.

\section{Background}

Effective health care delivery to the majority of HIV exposed infants worldwide, including those enrolled in prevention of mother-to-child transmission programs, is hampered by lack of access to an HIV diagnosis in infancy. Early testing can help HIV infected infants access treatment, provide psychosocial benefits for families of uninfected infants, and help programs for prevention of mother-to-child transmission of HIV monitor their effectiveness.

\section{Main objective}

The aim of the study was to report the impact of the early testing of HIV on the improved health care of the HIVinfected children and to describe the treatment outcomes in children ( $<18$ months of age).

\section{Methods}

Analysis of cumulative data gathered between April 2006 and December 2008 at Chey Chumneas Hospital including children born under PMTCT and the others attending pediatric services, which general pediatric out-patient include i) general pediatric out-patients, ii) nutrition rehabilitation centre, iii) in-patients care, iv) OI/HAART access and trained medical staff supported by NCHADS and Magna Children at Risk.

\section{Preliminary results}

During the study period, 174 HIV-exposed infants, less than 18 months, attending pediatric services were screened for HIV-1 infection. 137 (78,7\%) had an undetectable HIV-1 DNA/RNA viral load confirmed on a second blood samples. $37(21,2 \%)$ were found and confirmed HIV-1 infected, including 9 who received a PMTCT intervention. Four out of 37 HIV positive children were lost of follow up, 4 were transferred to another service, 7 died (two were already on HAART), 13 children were on OI prophylaxis only. Finally $12 / 37$ infected children started already HAART (3TC+d4T+NVP).

\section{Conclusion/perspectives}

The virological efficacy of treatments for the 12 children on HAART is currently under evaluation and will be presented. According to the new WHO guidelines for Paediatric HIV/ART Care, all the others infected children ( $\mathrm{n}=$ 13) will get HAART as soon as possible. The results of this study confirm that early testing is crucial to improve health care delivery to HIV-infected children in lowresource settings right now. Well adapted pediatric services are also needed for the complex follow-up of HIV infected children. 